\title{
Effects of knee sleeves on coordination of lower-limb segments in healthy adults during level walking and one-leg hopping
}

\author{
Chang-Yong Ko ${ }^{\text {Corresp., }}{ }^{1}$, Yunhee Chang ${ }^{1}$, Bora Jeong ${ }^{1}$, Sungjae Kang ${ }^{1}$, Jeicheong Ryu ${ }^{1}$, Gyoosuk Kim ${ }^{1}$ \\ ${ }^{1}$ Research Team, Rehabilitation Engineering Research Institute, Incheon, Republic of Korea \\ Corresponding Author: Chang-Yong Ko \\ Email address: monamicyko@gmail.com
}

The evaluation of multisegment coordination is important in gaining a better understanding of the gait and physical activities in humans. Therefore, this study aims to verify whether the use of knee sleeves affects the coordination of lower-limb segments during level walking and one-leg hopping. Eleven healthy male adults participated in this study. They were asked to walk $10 \mathrm{~m}$ on a level ground and perform one-leg hops with and without a knee sleeve. The segment angles and the response velocities of the thigh, shank, and foot were measured and calculated by using a motion analysis system. The phases between the segment angle and the velocity were then calculated. Moreover, the continuous relative phase (CRP) was calculated as the phase of the distal segment subtracted from the phase of the proximal segment and denoted as CRPTS (thigh-shank), CRPSF (shank-foot), and CRPTF (thigh-foot). The root mean square (RMS) values were used to evaluate the in-phase or out-of-phase states, while the standard deviation (SD) values were utilized to evaluate the variability in the stance and swing phases during level walking and in the preflight, flight, and landing phases during one-leg hopping. The walking velocity and the flight time improved when the knee sleeve was worn $(p<0.05)$. The segment angles of the thigh and shank also changed when the knee sleeve was worn during level walking and one-leg hopping. The RMS values of CRPTS and CRPSF in the stance phase and the RMS values of CRPSF in the preflight and landing phases changed ( $p$ $<0.05$ in all cases). Moreover, the SD values of CRPTS in the landing phase and the SD values of CRPSF in the preflight and landing phases increased ( $p<0.05$ in all cases). These results indicated that wearing a knee sleeve caused changes in segment kinematics and coordination. 
1 Effects of knee sleeves on coordination of lower-limb segments in healthy adults during

2

3

4

7

8

13 Corresponding author

$14 *$ Chang-Yong Ko

15 Rehabilitation Engineering Research Institute,

16 Incheon, Republic of Korea

17 TEL: +82-32-509-5244

18 FAX: +82-32-512-9794

19 E-mail: monamicyko@gmail.com/cyko@kcomwel.or.kr

\section{level walking and one-leg hopping}

Chang-Yong Ko, Yunhee Chang, Bora Jeong, Sungjae Kang, Jeicheong. Ryu, Gyoosuk Kim Research Team, Rehabilitation Engineering Research Institute, Incheon, Republic of Korea 


\section{Abstract}

The evaluation of multisegment coordination is important in gaining a better understanding of the gait and physical activities in humans. Therefore, this study aims to verify whether the use of knee sleeves affects the coordination of lower-limb segments during level walking and one-leg hopping. Eleven healthy male adults participated in this study. They were asked to walk $10 \mathrm{~m}$ on a level ground and perform one-leg hops with and without a knee sleeve. The segment angles and the response velocities of the thigh, shank, and foot were measured and calculated by using a motion analysis system. The phases between the segment angle and the velocity were then calculated. Moreover, the continuous relative phase (CRP) was calculated as the phase of the distal segment subtracted from the phase of the proximal segment and denoted as CRPTS (thigh-shank), CRPSF (shank-foot), and CRPTF (thigh-foot). The root mean square (RMS) values were used to evaluate the in-phase or out-of-phase states, while the standard deviation (SD) values were utilized to evaluate the variability in the stance and swing phases during level walking and in the preflight, flight, and landing phases during one-leg hopping. The walking velocity and the flight time improved when the knee sleeve was worn $(\mathrm{p}<0.05)$. The segment angles of the thigh and shank also changed when the knee sleeve was worn during level walking and one-leg hopping. The RMS values of CRPTS and CRPSF in the stance phase and the RMS values of CRPSF in the preflight and landing phases changed ( $\mathrm{p}<0.05$ in all cases). Moreover, the SD values of CRPTS in the landing phase and the SD values of CRPSF in the preflight and landing phases increased $(\mathrm{p}<0.05$ in all cases). These results indicated that wearing a knee sleeve caused changes in segment kinematics and coordination. 


\section{Introduction}

Knee sleeves are widely used to treat and prevent knee problems, such as knee osteoarthritis and pain, in both occupational and athletic settings. Beaudreuil et al. (2009) stated the clinical effectiveness of knee sleeve for knee osteoarthritis (Beaudreuil et al. 2009). Hrnack and Barber suggested that knee brace was one of the effective management methods of the pain of knee osteoarthritis (Hrnack \& Barber 2014). Some studies investigated the alterations in proprioception in humans wearing knee sleeves. Van Tiggelen et al. (2008) showed the positive effects of neoprene knee sleeves in overcoming the deficit in knee proprioception caused by muscle fatigue (Van Tiggelen et al. 2008). Meanwhile, Herrington et al. (2005) and Barrett et al. (2003) showed that the sense of the knee joint position improved in healthy subjects and adolescent female athletes wearing neoprene knee sleeves (Barrett 2003; Herrington et al. 2005).

Proprioception can affect the functional capacity and performance associated with motor control (Hettich et al. 2014; Riemann \& Lephart 2002; Serrien et al. 2001; Tunik et al. 2003). Therefore, some studies evaluated the effects of using a knee sleeve on the functional capacity and performance. Mortaza et al. (2012) showed that using a knee sleeve did not have any negative effects on the performance of a single-leg vertical jump and a crossover hop in healthy adults (Mortaza et al. 2012). Bryk et al. (2011) found that immediate positive effects were seen in the functional capacity of osteoarthritis patients wearing knee sleeves (Bryk et al. 2011). Several other researchers also evaluated the effects of using a knee sleeve on the kinematics and kinetics of walking or other physical activities. Collins et al. (2014) showed that during walking, the sagittalplane knee kinematics and kinetics improved in patients with osteoarthritis when they wore knee sleeves (Collins et al. 2014). In addition, Schween et al. (2015) showed that the use of knee sleeves 
64 had a positive effect on the frontal-plane knee kinematics and kinetics in osteoarthritis patients 65 during walking (Schween et al. 2015).

66

67

68

However, the abovementioned studies evaluated the kinematics and kinetics of a single joint/segment. The coordination of multiple segments of the lower extremity is required to accomplish a complex task, such as human walking, or any other physical activity with precise endpoint control. Therefore, evaluating the biomechanical features of a single joint/segment using traditional kinematic analyses may be insufficient in understanding the gait and physical activities in humans, and evaluating the multi-segment coordination is required. The continuous relative phase (CRP) is one of the most common parameters used to evaluate multi-joint/segment coordination. Many studies assessed the CRP to evaluate pathological and/or abnormal gait (Barela et al. 2000; Chiu et al. 2015; Chiu et al. 2010; Hamill et al. 2012; Yi et al. 2016). The CRP is calculated by monitoring the segment movement and its response velocity and thus it considers temporal and spatial patterns, which are important elements of motor coordination.

We hypothesized that a knee sleeve might alter joint or segment coordination based on the influences of a knee sleeve on the functional capacity and performance associated with the joint or segment kinematics (Bryk et al. 2011; Collins et al. 2014; Mortaza et al. 2012; Schween et al. 2015). However, to the best of our knowledge, no study has focused on the effects of using knee sleeves on joint or segment coordination. Therefore, we aim to verify whether the use of knee sleeves alters the coordination of the lower-limb segments during level walking and one-leg hopping. 
84

85

86

87

88

89

90

91

92

93

94

95

96

97

98

\section{Methods}

\subsection{Subjects}

Eleven male subjects with asymptomatic back, hip, knee, and ankle functions participated in this study. Their mean ( \pm SD) age, height, and weight were $24.8 \pm 2.8$ years, $179.8 \pm 8 \mathrm{~cm}$, and $80.6 \pm 15.5 \mathrm{~kg}$, respectively. The study was approved by the Human Ethics Committee of the Rehabilitation and Engineering Research Institute, Korea (RERE-IRB-20160721). Informed consent was obtained from all the subjects before the experiments.

\subsection{Experimental procedures}

The experiments were monitored using a three-dimensional (3D) motion analysis system (Motion Analysis, Santa Rosa, USA), which consisted of 12 infrared cameras (Raptor-4S, Motion Analysis, USA), four force plates $(600 \times 900 \mathrm{~mm}$, AMTI, USA), passive reflective markers, a data acquisition system, and a software package (Cortex Ver. 6.3).

We used Helen Hayes marker sets to place $1912.5 \mathrm{~mm}$ reflective markers on the anatomical landmarks of the lower limb. The markers were attached on the sacrum, anterior superior iliac spine (ASIS, bilaterally), lateral femoral epicondyle (bilaterally), calcaneus and malleolus (bilaterally), 2nd metatarsal head (bilaterally), and lower lateral 1/3 surface of both shanks and thighs (bilaterally). The kinematic data of all the markers and analog signals of the force plates were sampled at $120 \mathrm{~Hz}$ using real-time software (Cortex Ver. 6.3, Motion Analysis Corp., USA). The anthropometric data of each subject, including height and weight, were measured prior to the experiments. The subjects were later instructed to repeatedly walk on a $10 \mathrm{~m}$ walkway for 10 minutes to induce a natural gait pattern and to provide an adaptation period with 
106 the knee sleeve. The subjects walked at their self-selected walking speeds (SSWS) along the 107 gaitway. The marker 3D position data, the ground reaction forces and the real-time image data 108 were identified and measured by real-time software during the gait analysis. The data on each 109 marker were smoothed by Butterworth filters at $6 \mathrm{~Hz}$ (Kim et al. 2017).

We measured two activities in the experiments: walking and one-leg hop test. We chose

111

112

113

114

115

116

117

118

119

120

121

122

123

124

125

126

127

128

et al. 2003). The knee brace used in our study was a sleeve with a silicone patella pad (MEDI,

Germany). The subjects wore the sleeve only on their knee of their preferred legs, all right knee in this study. The knee sleeve for each subject was determined according to the sizing chart of the sleeve and fitted according to the manufacturer's guideline. We analyzed the change in the spatiotemporal and CRP parameters during walking and one-leg hopping before and after the knee brace was worn. The initial contact and toe off for the gait and hopping test were detected by using zero ground reaction force and visual inspection (Zeni et al. 2008).

All the subjects practiced walking before the actual gait analysis to induce a natural gait. They were then asked to walk at self-selected walking speed (Bohannon 1997). We obtained five successful gait trials, where a clean foot strike on the force plate and a maintained self-selected walking speed $( \pm 5 \%)$ within was defined as a successful trial. We observed the force exerted on the force plate through the foot contact period to verify the successful gait trials. For the one-leg hop test, the subjects practiced hopping once or twice, such that they could achieve the maximum jumping distance using one leg. We measured the values from three trials, then obtained their mean value. The one-leg hop activity was divided into the preflight, flight, and landing phases (Fig. 1(a)). The flight phase represents the period, in which the maximum jumping distance was 
129 achieved using one leg, and the landing phase represented the period after the subject lands on the

130 floor using the same leg. All the test procedures were randomly conducted by drawing lots.

131

132

\subsection{Measurement parameters}

133

134

135

136

137 3D space.

138

139

140

141

142

143

144

145

146

147

148

149

\subsubsection{CRPs}

\subsubsection{Spatiotemporal parameters}

A Cortex Ver. 6.3 was used to estimate the spatiotemporal parameters. The spatiotemporal parameters included walking velocity, cadence, step width, stride length, step length, and support time. These parameters were analyzed using the marker information, which contained data from a

\subsubsection{Segment angle}

A Cortex Ver. 6.3 was used to estimate the joint kinematics. The sagittal angles of the thigh, shank, and foot with the vertical axis to the ground were calculated by using the marker data obtained from the motion analysis system (Fig. 1 (b)). The angle was $0^{\circ}$ when perpendicular to the ground. The negative values of the angles of each segment indicated a clockwise direction to the reference axis, whereas the positive values implied a counter-clockwise direction. Fig. 1(c) shows specific sections of the segment angle curves. In particular, the initial or minimum angle indicated angle at initial contact or push off, respectively.

The segment velocity corresponding to the segment angle was calculated and interpolated from $0 \%$ to $100 \%$, including the stance and swing phases during a gait cycle and the preflight, flight, and landing phases during a one-leg hop. The angles and velocities were normalized 
150 between -1 and 1 . The phase portraits of the normalized velocity (y-axis, normV) against the 151 normalized angle (x-axis, norm $\theta$ ) during a gait or a one-leg hop test were then generated. The 152 calculated phase was sometimes outside the range of negative $180^{\circ}$ to positive $180^{\circ}$, resulting in 153 the increase in discontinuity of the phase portraits. Unwrapping was performed by a multiple of $154360^{\circ}$ to maintain the continuity of the phase portraits. The CRP angle between the normalized

155 velocity and the normalized angle was then calculated at each cycle as follows: $\mathrm{CRP}=\tan ^{-1} \frac{\text { normV }}{\text { norm } \theta}$ 156 . Subsequently, the average of the root mean square (RMS) and the standard deviation (SD) values 157 were calculated over each phase: the stance and swing phases during a gait cycle and the preflight, 158 flight, and landing phases during a one-leg hop. All the procedures were performed by using R 159 packages (Version 3.2.2, The R Foundation for Statistical Computing).

160

161

\subsection{Statistical analysis}

162

A paired t-test or a Wilcoxon t-test for non-uniformally distributed data was performed using SPSS v20 (IBM, USA) to verify the differences in the spatiotemporal parameters, segment angles, and RMS and SD values of CRPs between the cases with and without the knee sleeve. A Shapiro-Wilk test was also performed to evaluate the normality of the values. A p-value of less than 0.05 was considered significant.

\section{Results}

Table 1 lists the spatiotemporal parameters. No differences were found in any of the spatiotemporal parameters $(\mathrm{p}>0.05)$. Meanwhile, significant increases were observed in the flight 
171 time and the jump distance when the sleeve was worn ( $p>0.05$ in all cases) during the one-leg 172 hop.

Table 2 and Fig. 2 show the angles of each segment. The initial and minimum angles of

174 the thigh during level walking were lower for the subjects wore the sleeve $(\mathrm{p}=0.003$ and $\mathrm{p}=$ 1750.001 , respectively). The initial and minimum angles of the shank were higher for the the subjects 176 wore the sleeve $(\mathrm{p}=0.001$ and $\mathrm{p}<0.001$, respectively). No significant differences were found in 177 the other segment angles ( $p>0.05$ in all cases). were lower than those without $(\mathrm{p}=0.020)$. Meanwhile, the minimum angles of the shank for the subjects with the sleeve were higher than those without $(\mathrm{p}<0.001)$. No significant differences were found in the other segment angles ( $p>0.05$ in all cases).

Fig. 3 shows the CRPs, while Tables 3 and 4 present the RMS and SD values of the CRPs, respectively. The RMS value of CRPTS during the stance phase of walking was higher for the subjects while wearing the knee sleeve $(37.3 \pm 4.9$ vs. $39.1 \pm 3.4, p=0.032)$, whereas the RMS value of the CRPSF during the stance phase of walking was lower when the subjects wore the knee sleeve $(71.3 \pm 5.9$ vs. $69.0 \pm 6.7, \mathrm{p}=0.03)$. No differences were found in the other RMS values of the CRPs $(p>0.05)$. The SD value of CRPTS during the swing phase was significantly higher for the the subjects wore the sleeve $(23.5 \pm 5.4$ vs. $28.8 \pm 3.7, \mathrm{p}=0.006)$. No differences were observed in the other SD values of the CRPs $(p>0.05)$. The RMS values of CRPSF in the preflight and landing phases during the one-leg hop were higher for the subjects wore the sleeve $(88.8 \pm$ 13.1 vs. $97.4 \pm 1.8, \mathrm{p}=0.010$ and $78.3 \pm 17.5$ vs. $92.2 \pm 2.8, \mathrm{p}<0.001$, respectively). The SD 
193 for the subjects wore the sleeve $(39.1 \pm 7.2$ vs. $47.3 \pm 7.5, p=0.001,49.4 \pm 6.2$ vs. $52.5 \pm 9.7, p=$

1940.043 , and $42.3 \pm 10.0$ vs. $51.4 \pm 13.1, \mathrm{p}=0.028$, respectively). No differences were observed in 195 the other SD values of the CRPs $(p>0.05)$.

\section{Discussion}

The use of a knee sleeve altered the functional capacity and performance associated with 199 joint or segment kinematics. Although the evaluation of the multisegment coordination is more important in gaining a better understanding of the gait and physical activities in humans than that of a single segment, no previous studies have evaluated the effects of a knee sleeve on segment coordination. Therefore, the present study aimed to verify whether the use of knee sleeves affects the coordination of the lower-limb segments during level walking and one-leg hopping. the experiments. These results implied that the knee sleeve less altered the subject performance during the gait and the one-leg hop, which was consistent with the inferences made in previous studies (Bryk et al. 2011; Mortaza et al. 2012). the knee sleeve was lower, whereas that of the shank was higher during level walking. The minimum thigh angle decreased, while the minimum shank angle increased for the subjects with the knee sleeve. These results might imply that wearing the knee brace altered the segment angles during level walking, which was consistent with the observation made by (Collins et al. 2014). The knee motion might be restricted by the knee sleeve in the swing phase. However, the 214 differences in the angles of the thigh and the shank between the subjects with and without the knee 
215 brace were less than $5^{\circ}$, which was the minimum angle clinically acceptable for identifying the

216 differences between sessions in healthy adults during gait (Wilken et al. 2012). Although the angle

217 trajectories for the thigh and the shank completely shifted throughout the level walking activity,

218 the study results implied that wearing the knee sleeve only slightly altered the segment angle. The

219 minimum angles of the thigh and the shank during the one-leg hop were lower $\left(3.5^{\circ}\right)$ and higher

$220\left(6.3^{\circ}\right)$, respectively, for the subjects with the knee sleeve than those without. No kinematic

221 differences were observed in the foot angles. The minimum angles of the thigh and the shank were

222 normally observed in the late preflight phase. These results indicated that the knee flexion in the

223 late preflight phase was suppressed by the knee sleeve. No alterations were observed in the foot

224 angle during level walking and one-leg hopping. Overall, the effects of the knee sleeve on the

225 segment angles might be dependent on the type of activity: the effects during normal walking were

226 less than those during one-leg hopping.

In terms of the coordinative phase between the segments, the RMS value of CRPTS in the

228

229

230

231

232

233

234

235

236

237 stance phase changed during level walking and particularly increased for the subjects with the knee sleeve. This finding implied a large out-of-phase state between the thigh and the shank (Lamb \& Stöckl 2014). In contrast, the RMS value of CRPSF in the stance phase decreased for the subjects with the knee sleeve, thereby implying a large in-phase state between the shank and the foot (Lamb \& Stöckl 2014). These results indicated that the knee sleeve might affect the phase between the segments in the stance phase, but not in the swing phase. Although the angle trajectories of each segment between the cases without and with the knee sleeve were similar, the phase differences were observed between each segment. These results might be attributed to the CRP features, in which the direction of the angle movement and the angle velocity were considered (Lamb \& Stöckl 2014). The RMS values of CRPSF in the preflight and landing phases during one-leg hopping 
238 increased for the subjects with the knee sleeve, indicating an out-of-phase state between the shank 239 and the foot (Lamb \& Stöckl 2014). However, no phase changes were observed in the flight phase, 240 which indicated that the knee sleeve might affect the phase between the segments in the preflight 241 and landing phases. Overall, the knee sleeve altered the phase between the segments, particularly 242 in the weight-bearing period or the period of foot contact with the ground in the stance phase 243 during level walking and in the preflight and landing phases during one-leg hopping. These results 244 might be attributed to the proprioceptive enhancement effect of the knee sleeve on the knee (Barrett 2003; Herrington et al. 2005; Van Tiggelen et al. 2008) and/or the ankle during the weight-bearing period or period of foot contact with the ground to alleviate the load on the knee.

In terms of the coordinative variability between the segments, the variability during tasks could be interpreted in two ways. Greater variability between the segments or joints was more preferable in the stance phase or the support period, whereas lower variability was more preferable in the swing phase. The lower limb should persistently recognize the terrain to maintain the balance or stability of the body, control the joint positions, and perform tasks (Yi et al. 2016) in the stance phase or the support period. Therefore, greater variability was more preferable. Greater variability would also contribute to the load distribution or force on the joint and tissues or suppress the load concentration or force in a small area, thereby leading to the prevention of overuse injuries (Hamill et al. 2012). Meanwhile, lower variability might be beneficial in the swing phase to reduce the effort of controlling joints (Chen et al. 2015). The SD value of CRPTS in the swing phase changed during level walking (i.e., it particularly increased for the subjects with the knee sleeve, implying a greater variability in the knee for the subjects with the knee brace in the swing phase. Therefore, more coordination patterns should be employed to control the limb during the swing phase of gait 260 (Chen et al. 2015). This result might be attributed to a tendency to restrict knee motion in the swing 
261 phase, as mentioned above. The influence of variability in the swing phase or the unsupported

262 period on injuries was not studied. Hence, whether the higher variability in the swing phase altered

263 the occurrence of injuries was unclear.

264

265

266

267

268

269

270

271

272

273

274

275

276

277

278

279

280

281

282

283
The SD value of CRPSF in the preflight phase and the SD values of CRPTS and CRPSF during landing increased during the single leg hops. The SD value of the joint increased when the knee sleeve was worn, thereby indicating an increase in the joint variability (Hamill et al. 2012).

Furthermore, the joint type altered by the knee sleeve was likely to be dependent on the activity conditions: the ankle in the preflight phase and the ankle and the knee in the landing phase. The ankle played the most critical role in maintaining balance during the single-leg stance (Riemann et al. 2003). Meanwhile, the proximal joints played an increased role in maintaining balance under more challenging conditions, such as form surface and removal of vision (Riemann et al. 2003). Therefore, wearing the sleeve could improve the subjects' abilities to dynamically balance themselves during a single-leg stance through an increase in the stability of the proximal joints (i.e., knee) that play critical roles in maintaining balance during tasks, such as single leg hopping. In addition, the knee and ankle stability in the landing and preflight phases might be enhanced. Therefore, wearing the knee sleeve could contribute to the prevention of overuse injuries in the knee and/or the ankle via enhancement of the joint stability (Hamill et al. 2012).

Injuries frequently occur when a player is in a fatigued state (Van Tiggelen et al. 2008), and they occur in many sports activities. Therefore, further studies, such as those about athletes, should consider these issues through our evaluation methods to know how a knee sleeve affects the segment kinematics and coordination. In addition to the kinematic analysis, the assessment of the kinetic parameters, such as moment or force, is also needed to evaluate the joint or segment loading or force and understand the effects of knee sleeves on joint mechanics and loading and 
284 how a knee sleeve may affect the risk of injury. Several studies found that the knee sleeve might 285 be less effective in young healthy subjects (Bottoni et al. 2013) and might produce inhibitory 286 effects in subjects, who are not accustomed to wearing it (Baltaci et al. 2011). The subjects in the 287 present study are young and healthy and not accustomed to wearing the knee sleeve. Nevertheless, 288 the knee sleeve less altered the jumping (i.e., hop distance) and gait performance However, we did 289 not evaluate the potential effect of an acclimation period of wearing the knee sleeve, and how this 290 acclimation may potentially affect their results. Further studies to address these issues are 291 required.

\section{Conclusion}

This study aimed to verify whether the use of knee sleeves affects the coordination of lower-limb

295 segments during level walking and one-leg hopping. Herein, the knee sleeve had no significant effects on the jumping and gait performance. In addition, the knee sleeve affected the kinematics of the thigh and the shank, but not of the foot, during level walking and single leg hops. Moreover, the knee sleeve altered the segment coordination in the lower limb during the gait and single leg hop tasks. 
301

302

303

304

305

306

307

308

309

310

311

312

313

314

315

316

317

318

319

320

321

322

323

324

325

326

327

328

329

330

331

332

333

334

335

336

337

\section{References}

Baltaci G, Aktas G, Camci E, Oksuz S, Yildiz S, and Kalaycioglu T. 2011. The effect of prophylactic knee bracing on performance: balance, proprioception, coordination, and muscular power. Knee Surgery, Sports Traumatology, Arthroscopy 19:1722-1728.

Barela JA, Whitall J, Black P, and Clark JE. 2000. An examination of constraints affecting the intralimb coordination of hemiparetic gait. Human Movement Science 19:251-273.

Barrett GB. 2003. The Effects of Neoprene Sleeve Application on Knee Joint Proprioception in Adolescent Female Athletes.

Beaudreuil J, Bendaya S, Faucher M, Coudeyre E, Ribinik P, Revel M, and Rannou F. 2009. Clinical practice guidelines for rest orthosis, knee sleeves, and unloading knee braces in knee osteoarthritis. Joint Bone Spine 76:629-636.

Bohannon RW. 1997. Comfortable and maximum walking speed of adults aged 20—79 years: reference values and determinants. Age and ageing 26:15-19.

Bottoni G, Herten A, Kofler P, Hasler M, and Nachbauer W. 2013. The effect of knee brace and knee sleeve on the proprioception of the knee in young non-professional healthy sportsmen. The Knee 20:490-492.

Bryk FF, Jesus JFd, Fukuda TY, Moreira EG, Marcondes FB, and Santos MGd. 2011. Immediate effect of the elastic knee sleeve use on individuals with osteoarthritis. Revista brasileira de reumatologia 51:440-446.

Chen H-L, Lu T-W, and Chou L-S. 2015. Effect of concussion on inter-joint coordination during dividedattention gait. Journal of medical and biological engineering 35:28-33.

Chiu S-L, Chang C-C, Dennerlein JT, and Xu X. 2015. Age-related differences in inter-joint coordination during stair walking transitions. Gait \& posture 42:152-157.

Chiu S-L, Lu T-W, and Chou L-S. 2010. Altered inter-joint coordination during walking in patients with total hip arthroplasty. Gait \& posture 32:656-660.

Collins A, Blackburn T, Olcott C, Jordan JM, Yu B, and Weinhold P. 2014. A kinetic and kinematic analysis of the effect of stochastic resonance electrical stimulation and knee sleeve during gait in osteoarthritis of the knee. Journal of applied biomechanics 30:104-112.

Grindem H, Logerstedt D, Eitzen I, Moksnes H, Axe MJ, Snyder-Mackler L, Engebretsen L, and Risberg MA. 2011. Single-legged hop tests as predictors of self-reported knee function in nonoperatively treated individuals with anterior cruciate ligament injury. The American journal of sports medicine 39:2347-2354.

Hamill J, Palmer C, and Van Emmerik REA. 2012. Coordinative variability and overuse injury. BMC Sports Science, Medicine and Rehabilitation 4:1.

Herrington L, Simmonds C, and Hatcher J. 2005. The effect of a neoprene sleeve on knee joint position sense. Research in Sports Medicine 13:37-46.

Hettich G, Assländer L, Gollhofer A, and Mergner T. 2014. Human hip-ankle coordination emerging 
from multisensory feedback control. Human Movement Science 37:123-146.

Hrnack SA, and Barber FA. 2014. Managing the pain of knee osteoarthritis. The Physician and sportsmedicine 42:63-70.

Kim S-B, Ko C-Y, Son J, Kang S, Ryu J, and Mun M. 2017. Relief of knee flexion contracture and gait improvement following adaptive training for an assist device in a transtibial amputee: A case study. Journal of Back and Musculoskeletal Rehabilitation 30:371-381.

Lamb PF, and Stöckl M. 2014. On the use of continuous relative phase: Review of current approaches and outline for a new standard. Clinical Biomechanics 29:484-493.

Mortaza N, Ebrahimi I, Jamshidi AA, Abdollah V, Kamali M, Abas WABW, and Osman NAA. 2012. The effects of a prophylactic knee brace and two neoprene knee sleeves on the performance of healthy athletes: a crossover randomized controlled trial. PloS one 7:e50110.

Riemann BL, and Lephart SM. 2002. The sensorimotor system, part II: the role of proprioception in motor control and functional joint stability. Journal of athletic training 37:80.

Riemann BL, Myers JB, and Lephart SM. 2003. Comparison of the ankle, knee, hip, and trunk corrective action shown during single-leg stance on firm, foam, and multiaxial surfaces. Archives of physical medicine and rehabilitation 84:90-95.

Schween R, Gehring D, and Gollhofer A. 2015. Immediate Effects of an Elastic Knee Sleeve on Frontal Plane Gait Biomechanics in Knee Osteoarthritis. PloS one 10:e0115782.

Serrien DJ, Li Y, Steyvers M, Debaere F, and Swinnen SP. 2001. Proprioceptive regulation of interlimb behavior: interference between passive movement and active coordination dynamics. Experimental brain research 140:411-419.

Tunik E, Poizner H, Levin MF, Adamovich SV, Messier J, Lamarre Y, and Feldman AG. 2003. Arm-trunk coordination in the absence of proprioception. Experimental brain research 153:343-355.

Van Tiggelen D, Coorevits P, and Witvrouw E. 2008. The use of a neoprene knee sleeve to compensate the deficit in knee joint position sense caused by muscle fatigue. Scandinavian journal of medicine \& science in sports 18:62-66.

Van Uden CJT, Bloo JKC, Kooloos JGM, Van Kampen A, De Witte J, and Wagenaar RC. 2003. Coordination and stability of one-legged hopping patterns in patients with anterior cruciate ligament reconstruction: preliminary results. Clinical Biomechanics 18:84-87.

Wilken JM, Rodriguez KM, Brawner M, and Darter BJ. 2012. Reliability and minimal detectible change values for gait kinematics and kinetics in healthy adults. Gait \& posture 35:301-307.

Yi LC, Sartor CD, Souza FT, and Sacco ICN. 2016. Intralimb Coordination Patterns in Absent, Mild, and Severe Stages of Diabetic Neuropathy: Looking Beyond Kinematic Analysis of Gait Cycle. PloS one 11:e0147300.

Zeni JA, Richards JG, and Higginson JS. 2008. Two simple methods for determining gait events during treadmill and overground walking using kinematic data. Gait \& posture 27:710-714. 

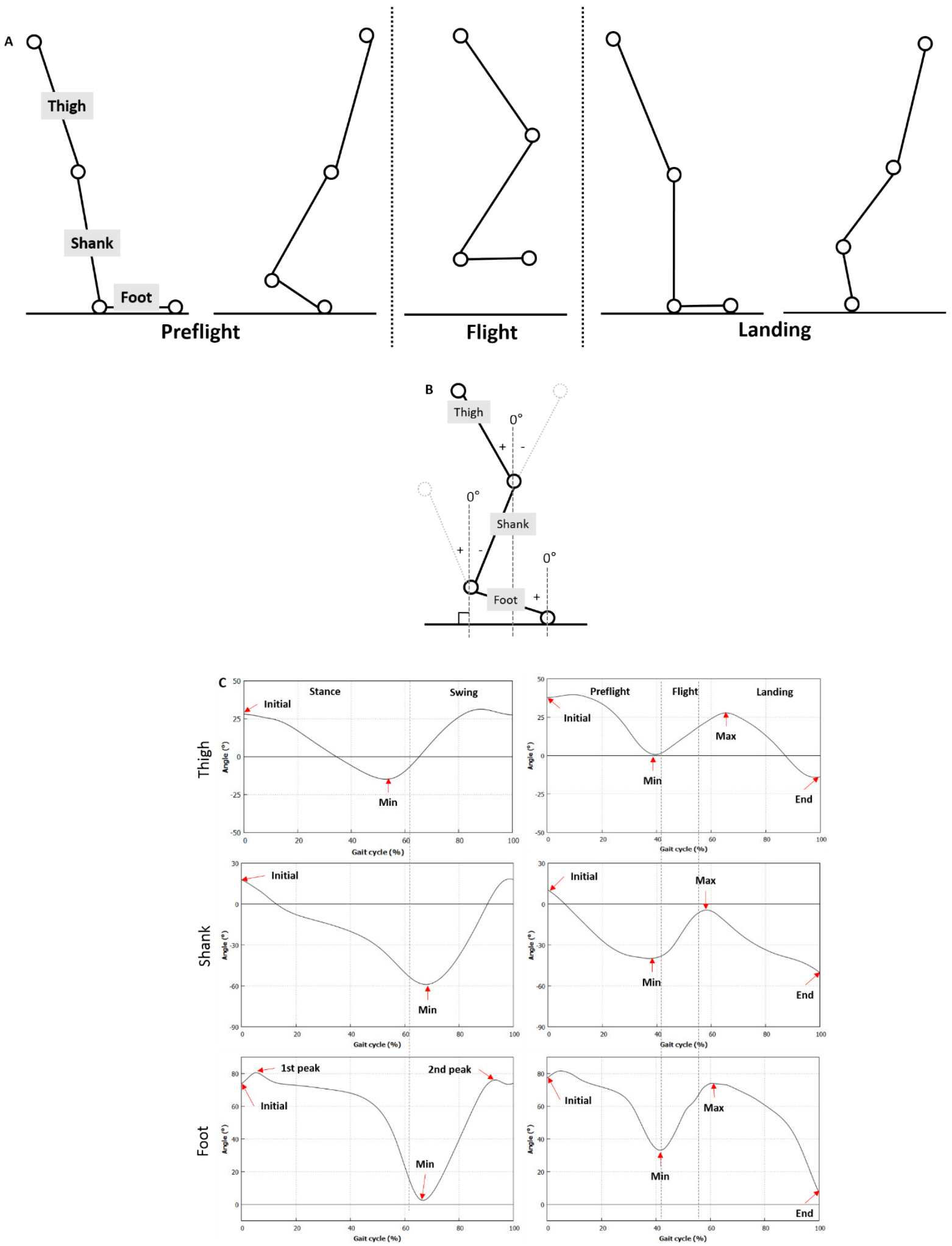

Gait

One leg hop

Fig. 1 Definition of the segment angle and the phase and specific values of the segment angle. (a) The one-leg hop activity is divided into the preflight, flight, and landing phases. (b) The sagittal angles of the thigh, shank, and foot with the vertical axis to the ground are calculated by using the marker data obtained from the motion analysis system. 
379 (c) Specific sections of the segment angle curves are defined. 

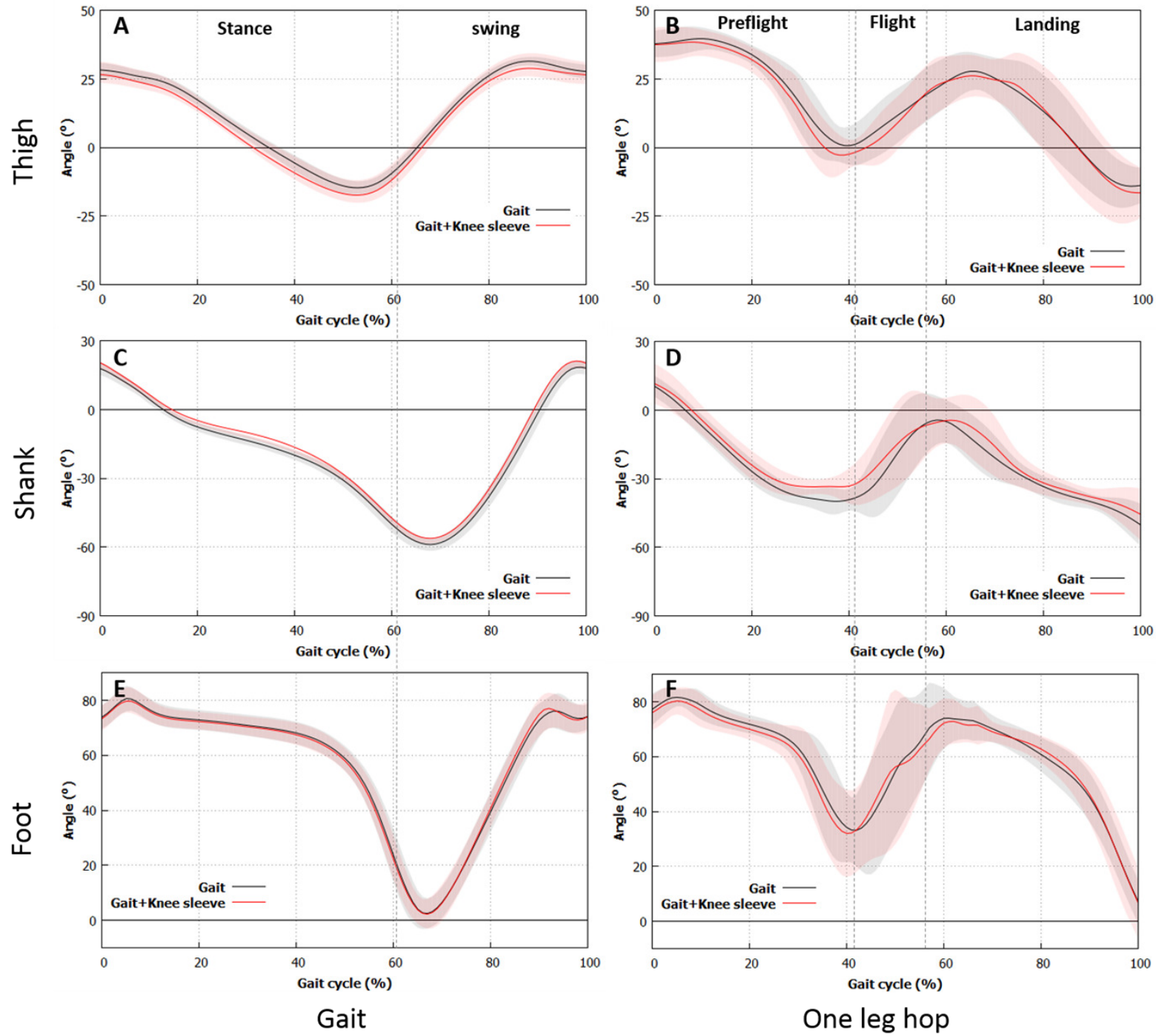

Fig. 2 Variations in the segment angle. Differences in the segment angles in the thigh and the shank of the subjects with the sleeve and those without are found during gait and one-leg hop. (a), (b) Thigh. (c), (d) Shank. (e), (f) Foot. (a), (c), (e) Gait, (b), (d), (f) One leg hop. 

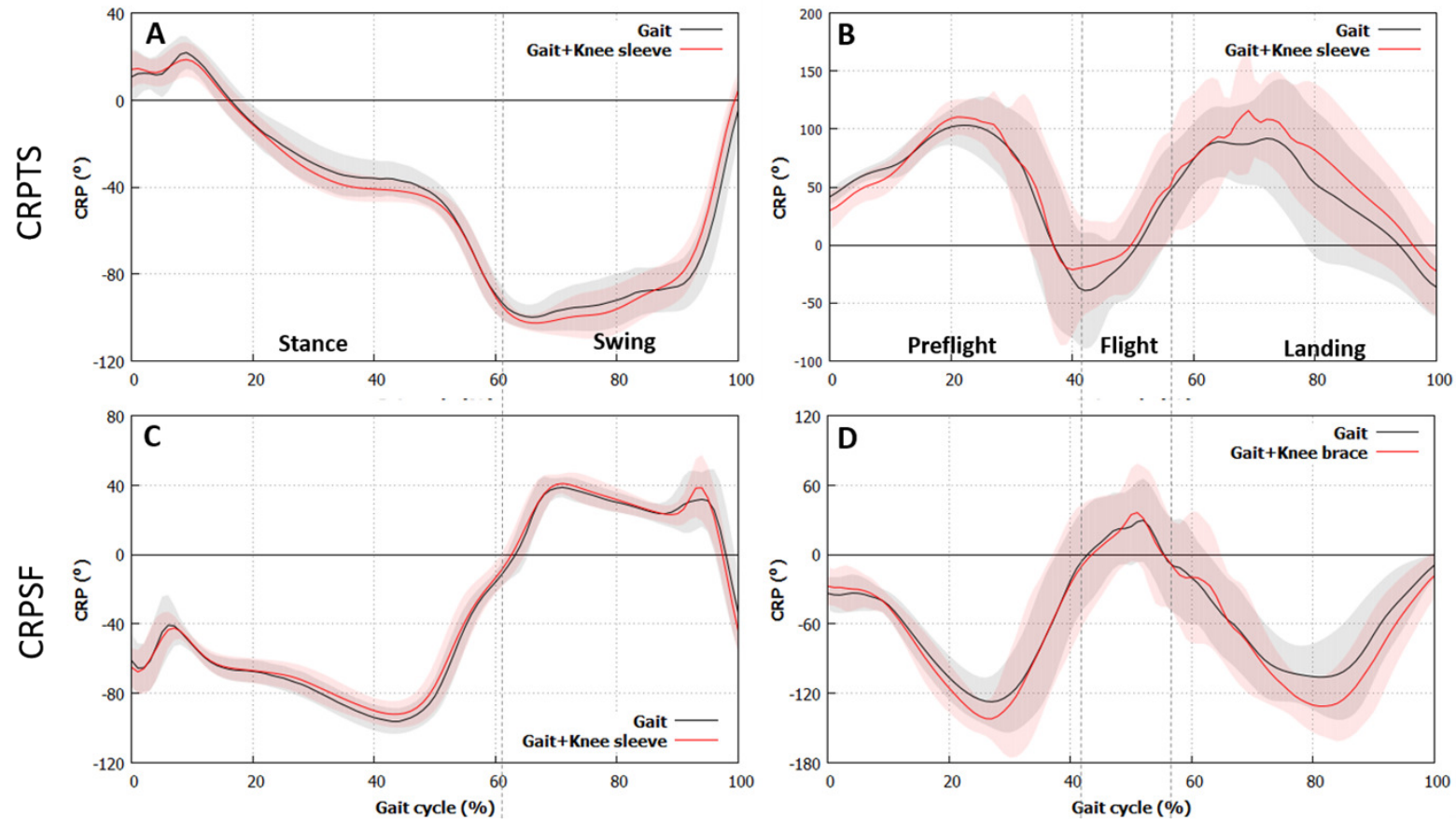

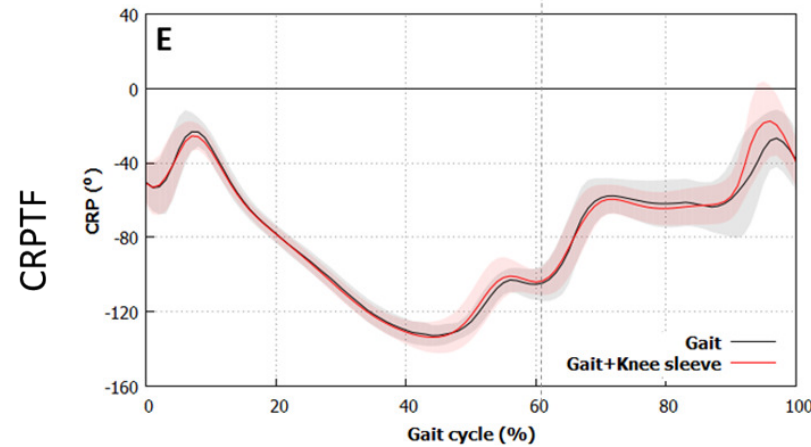

Gait

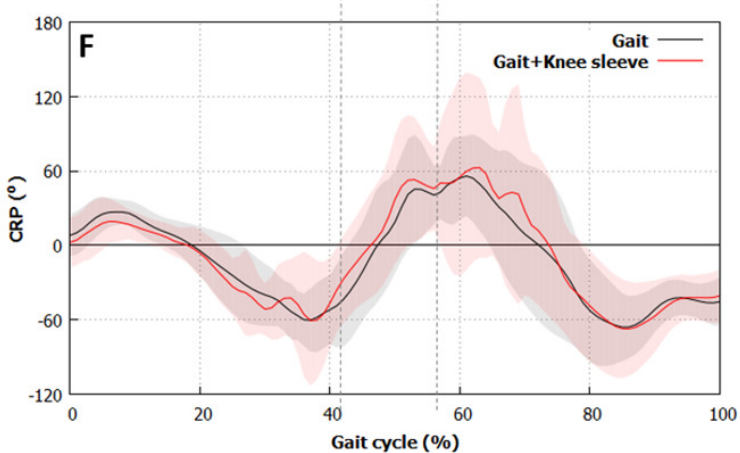

One leg hop
385

Fig. 3 CRP results. Differences in CRPTS and CRPSF of the subjects with the sleeve and those without are found during gait and one-leg hop. (a), (b) Thigh. (c), (d) Shank. (e), (f) Foot. (a), (c), (e) Gait, (b), (d), (f) One leg hop. 
390 Table 1. Mean \pm S.D. values of the spatiotemporal parameters. Significant differences on the spatiotemporal 391 parameters of the subjects with knee sleeve and those without are found during gait and one-leg hop.

\begin{tabular}{ccccc}
\hline & Parameter & No sleeve & Sleeve & p-Value \\
\hline \hline Step width (cm) & $12.1 \pm 2.3$ & $12.9 \pm 2.7$ & 0.178 \\
& Velocity (cm/s) & $136.0 \pm 6.9$ & $140.1 \pm 7.4$ & 0.078 \\
Gait & Stride length (cm) & $147.2 \pm 10.2$ & $149.8 \pm 10.1$ & 0.120 \\
& Cadence & $110.9 \pm 7.0$ & $112.3 \pm 4.9$ & 0.104 \\
& Stance (\%) & $62.6 \pm 1.7$ & $62.3 \pm 1.4$ & 0.122 \\
& Swing (\%) & $37.4 \pm 1.7$ & $37.7 \pm 1.4$ & 0.122 \\
\hline One-leg hop & Flight time (s) & $0.2 \pm 0.0$ & $0.3 \pm 0.0$ & 0.159 \\
& Distance (cm) & $119.6 \pm 8.9$ & $117.9 \pm 7.0$ & 0.151 \\
\hline
\end{tabular}

392 
394

\begin{tabular}{|c|c|c|c|c|c|c|c|}
\hline & & \multicolumn{3}{|c|}{ Gait } & \multicolumn{3}{|c|}{ One-leg hop } \\
\hline & & No sleeve & With sleeve & $\mathrm{p}$-Value & No sleeve & With sleeve & $\mathrm{p}$-Value \\
\hline \multirow{3}{*}{ Thigh } & Initial & $28.2 \pm 2.7$ & $26.6 \pm 3.0^{*}$ & 0.003 & $37.8 \pm 4.9$ & $37.5 \pm 6.3$ & 0.389 \\
\hline & Min & $-14.9 \pm 2.4$ & $\begin{array}{c}-17.6 \pm \\
2.8^{*}\end{array}$ & 0.001 & $-5.3 \pm 4.0$ & $-8.8 \pm 3.8^{*}$ & 0.020 \\
\hline & Max & $\mathrm{N} / \mathrm{A}$ & $\mathrm{N} / \mathrm{A}$ & & $33.2 \pm 4.5$ & $33.9 \pm 4.4$ & 0.311 \\
\hline \multirow{3}{*}{ Shank } & Initial & $17.8 \pm 2.9$ & $20.3 \pm 2.7^{*}$ & 0.001 & $10.3 \pm 4.6$ & $11.5 \pm 8.8$ & 0.269 \\
\hline & Min & $-59.2 \pm 2.6$ & $\begin{array}{c}-56.4 \pm \\
2.02 *\end{array}$ & $<0.001$ & $-43.1 \pm 4.4$ & $\begin{array}{c}-37.4 \pm \\
3.8^{*}\end{array}$ & $<0.001$ \\
\hline & $\operatorname{Max}$ & $\mathrm{N} / \mathrm{A}$ & $\mathrm{N} / \mathrm{A}$ & $\mathrm{N} / \mathrm{A}$ & $5.0 \pm 4.6$ & $8.2 \pm 4.0^{*}$ & 0.009 \\
\hline \multirow{5}{*}{ Foot } & Initial & $73.9 \pm 4.3$ & $73.3 \pm 4.4$ & 0.139 & $77.3 \pm 5.8$ & $76.1 \pm 6.4$ & 0.227 \\
\hline & $\begin{array}{c}1 \mathrm{st} \\
\text { peak }\end{array}$ & $81.7 \pm 4.6$ & $80.8 \pm 4.3$ & 0.113 & $\mathrm{~N} / \mathrm{A}$ & N/A & N/A \\
\hline & Min & $1.3 \pm 5.7$ & $1.3 \pm 5.2$ & 0.493 & $19.5 \pm 6.0$ & $18.5 \pm 5.4$ & 0.161 \\
\hline & $\begin{array}{l}\text { 2nd } \\
\text { peak }\end{array}$ & $78.3 \pm 6.4$ & $78.6 \pm 6.2$ & 0.292 & $\mathrm{~N} / \mathrm{A}$ & N/A & N/A \\
\hline & $\operatorname{Max}$ & $\mathrm{N} / \mathrm{A}$ & N/A & $\mathrm{N} / \mathrm{A}$ & $80.2 \pm 8.3$ & $79.0 \pm 7.9$ & 0.151 \\
\hline
\end{tabular}

Table 2. Segment angles. The initial and minimum angles of the thigh and the shank during gait for the subjects with the sleeve are different from those without. The minimum angles of the thigh and the shank during the one-leg hop for the subjects with the sleeve are also different from those without. 
399 Table 3. Mean \pm S.D. values of RMS of CRPs. The RMS value of CRPTS in the stance during gait is 400 higher for the subjects with the sleeve than those without, whereas that of CRPSF in the stance is 401 lower for the subjects with the sleeve than those without.

\begin{tabular}{|c|c|c|c|c|c|c|c|c|c|c|}
\hline \multirow[t]{2}{*}{ RMS } & & \multicolumn{3}{|c|}{ CRPTS } & \multicolumn{3}{|c|}{ CRPSF } & \multicolumn{3}{|c|}{ CRPTF } \\
\hline & & $\begin{array}{c}\text { No } \\
\text { sleeve }\end{array}$ & $\begin{array}{c}\text { With } \\
\text { sleeve }\end{array}$ & $\begin{array}{c}\mathrm{p}- \\
\text { value }\end{array}$ & $\begin{array}{c}\text { No } \\
\text { sleeve }\end{array}$ & $\begin{array}{c}\text { With } \\
\text { sleeve }\end{array}$ & $\begin{array}{c}\mathrm{p}- \\
\text { value }\end{array}$ & $\begin{array}{c}\text { No } \\
\text { sleeve }\end{array}$ & $\begin{array}{l}\text { With } \\
\text { sleeve }\end{array}$ & $\begin{array}{c}\mathrm{p}- \\
\text { value }\end{array}$ \\
\hline \multirow{2}{*}{ Gait } & Stance & $\begin{array}{c}37.3 \\
\pm 4.9\end{array}$ & $\begin{array}{c}39.1 \\
\pm 3.4\end{array}$ & 0.032 & $\begin{array}{r}71.3 \\
\pm 5.9\end{array}$ & $\begin{array}{r}69.0 \\
\pm 6.7\end{array}$ & 0.030 & $\begin{array}{c}97.8 \\
\pm 4.2\end{array}$ & $\begin{array}{r}97.8 \\
\pm 5.3\end{array}$ & 0.493 \\
\hline & Swing & $\begin{array}{l}85.4 \\
\pm 8.6 \\
\end{array}$ & $\begin{array}{r}86.0 \\
\pm 7.5 \\
\end{array}$ & 0.377 & $\begin{array}{r}30.0 \\
\pm 5.0 \\
\end{array}$ & $\begin{array}{r}30.9 \\
\pm 4.5 \\
\end{array}$ & 0.101 & $\begin{array}{c}63.3 \\
\pm 10.8 \\
\end{array}$ & $\begin{array}{r}62.7 \\
\pm 8.6 \\
\end{array}$ & 0.395 \\
\hline \multirow{3}{*}{$\begin{array}{l}\text { One- } \\
\text { leg } \\
\text { hop }\end{array}$} & Preflight & $\begin{array}{r}78.0 \\
\pm 9.8\end{array}$ & $\begin{array}{r}81.0 \\
\pm 7.9\end{array}$ & 0.131 & $\begin{array}{c}88.8 \\
\pm 13.1\end{array}$ & $\begin{array}{r}97.4 \\
\pm 1.8\end{array}$ & 0.010 & $\begin{array}{c}35.4 \\
\pm 7.9\end{array}$ & $\begin{array}{c}36.8 \\
\pm 6.1\end{array}$ & 0.268 \\
\hline & Flight & $\begin{array}{c}47.3 \\
\pm 8.8\end{array}$ & $\begin{array}{r}43.6 \\
\pm 7.5\end{array}$ & 0.053 & $\begin{array}{c}27.2 \\
\pm 19.6\end{array}$ & $\begin{array}{c}28.9 \\
\pm 24.2\end{array}$ & 0.297 & $\begin{array}{c}51.3 \\
\pm 8.9\end{array}$ & $\begin{array}{c}54.2 \\
\pm 17.4\end{array}$ & 0.268 \\
\hline & Landing & $\begin{array}{c}74.6 \\
\pm 18.7\end{array}$ & $\begin{array}{c}87.1 \\
\pm 20.9\end{array}$ & 0.065 & $\begin{array}{c}78.3 \\
\pm 17.5\end{array}$ & $\begin{array}{c}92.2 \\
\pm 2.8\end{array}$ & $<0.001$ & $\begin{array}{c}56.6 \\
\pm 11.4\end{array}$ & $\begin{array}{c}62.8 \\
\pm 26.9\end{array}$ & 0.256 \\
\hline
\end{tabular}

402

403 
404 Table 4. Mean \pm S.D. values of SD of CRPs. The SD value of CRPTS in the swing phase during gait is significantly 405 higher for the subjects with the sleeve than those without. The CRPSF values in the preflight and landing phases 406 during the one-leg hop are higher for the subjects with the sleeve than those without. The SD values of CRPSF in the 407 preflight phase and the SD values of CRPTS and CRPSF in the landing phase are higher for the subjects with the 408 sleeve than those without.

\begin{tabular}{|c|c|c|c|c|c|c|c|c|c|c|}
\hline \multirow[t]{2}{*}{$\mathrm{SD}$} & & \multicolumn{3}{|c|}{ CRPTS } & \multicolumn{3}{|c|}{ CRPSF } & \multicolumn{3}{|c|}{ CRPTF } \\
\hline & & $\begin{array}{c}\text { No } \\
\text { sleeve }\end{array}$ & $\begin{array}{c}\text { With } \\
\text { sleeve }\end{array}$ & $\begin{array}{c}\mathrm{p}- \\
\text { value }\end{array}$ & $\begin{array}{c}\text { No } \\
\text { sleeve }\end{array}$ & $\begin{array}{l}\text { With } \\
\text { sleeve }\end{array}$ & $\begin{array}{c}\mathrm{p}- \\
\text { value }\end{array}$ & $\begin{array}{c}\text { No } \\
\text { sleeve }\end{array}$ & $\begin{array}{c}\text { With } \\
\text { sleeve }\end{array}$ & $\begin{array}{c}\mathrm{p}- \\
\text { value }\end{array}$ \\
\hline \multirow{2}{*}{ Gait } & Stance & $\begin{array}{c}29.0 \\
\pm 2.8\end{array}$ & $\begin{array}{r}29.6 \\
\pm 3.1\end{array}$ & 0.227 & $\begin{array}{l}21.6 \\
\pm 2.0\end{array}$ & $\begin{array}{r}20.5 \\
\pm 2.8\end{array}$ & 0.100 & $\begin{array}{c}35.4 \\
\pm 2.7\end{array}$ & $\begin{array}{r}35.0 \\
\pm 2.1\end{array}$ & 0.342 \\
\hline & Swing & $\begin{array}{c}23.5 \\
\pm 5.4\end{array}$ & $\begin{array}{r}28.8 \\
\pm 3.7\end{array}$ & 0.006 & $\begin{array}{r}20.0 \\
\pm 5.1\end{array}$ & $\begin{array}{r}20.9 \\
\pm 4.7\end{array}$ & 0.309 & $\begin{array}{c}20.9 \\
\pm 4.8\end{array}$ & $\begin{array}{c}22.5 \\
\pm 4.6\end{array}$ & 0.143 \\
\hline \multirow{3}{*}{$\begin{array}{l}\text { One- } \\
\text { leg } \\
\text { hop }\end{array}$} & Preflight & $\begin{array}{c}36.1 \\
\pm 5.2\end{array}$ & $\begin{array}{c}38.3 \\
\pm 3.6\end{array}$ & 0.080 & $\begin{array}{c}39.1 \\
\pm 7.2\end{array}$ & $\begin{array}{r}47.3 \\
\pm 7.5\end{array}$ & 0.001 & $\begin{array}{c}33.1 \\
\pm 7.0\end{array}$ & $\begin{array}{r}33.9 \\
\pm 5.5\end{array}$ & 0.342 \\
\hline & Flight & $\begin{array}{c}40.3 \\
\pm 12.1\end{array}$ & $\begin{array}{c}38.1 \\
\pm 13.5\end{array}$ & 0.339 & $\begin{array}{c}17.2 \\
\pm 7.6\end{array}$ & $\begin{array}{r}19.0 \\
\pm 7.8\end{array}$ & 0.164 & $\begin{array}{c}48.6 \\
\pm 13.6\end{array}$ & $\begin{array}{c}47.0 \\
\pm 18.0\end{array}$ & 0.370 \\
\hline & Landing & $\begin{array}{r}49.4 \\
\pm 6.2\end{array}$ & $\begin{array}{r}52.5 \\
\pm 6.7\end{array}$ & 0.043 & $\begin{array}{c}42.3 \\
\pm 10.0\end{array}$ & $\begin{array}{c}51.4 \\
\pm 13.1\end{array}$ & 0.028 & $\begin{array}{c}50.7 \\
\pm 9.1\end{array}$ & $\begin{array}{c}56.1 \\
\pm 24.8\end{array}$ & 0.243 \\
\hline
\end{tabular}

409

410

411 